\title{
JOSEPH RATZINGER- BENEDICTO XVI. UNA VIDA EN CLAVE DE RENUNCIAS
}

\section{JOSEPH RATZINGER-BENEDICTO XVI, A LIFE IN A KEY OF RENUNCIATION}

\author{
ÁNGEL LUIS LORENZO FRANCISCO \\ I.S.CC.RR. "Sta. Ma de Guadalupe"
}

\section{RESUMEN}

La figura del Papa-Teólogo es totalmente trascendente en el escenario académico y teológico mundial. En este artículo, desde un punto de vista más personal y humano, intento mostrar como en la vida de J. Ratzinger-Benedicto XVI la renuncia (Abgehen) es el hilo de oro, que acompaña toda su historia. Desde sus comienzos como Catedrático, hasta su renuncia papal, sus decisiones fueron valientes, alejadas de cualquier interés personal, y desde una vinculación a la Iglesia, como lugar de servicio en la Fe.

Palabras clave: Ratzinger-Benedicto XVI, renuncia, decisión, libertad.

\section{ABSTRACT}

The figure of the Pope-Theologian is totally transcendent in the academic and theological world scenario. In this article, from a more personal and human point of view, I try to show how in the life of J. Ratzinger-Benedict XVI renunciation (Abgehen) is the golden thread, which accompanies all his history. From his beginnings as a Professor, 
until his papal resignation, his decisions were courageous, far from any personal interest, and from a bond with the Church, as a place of service in the Faith.

Keywords: Ratzinger-Benedicto XVI, resignation, decisions, liberty.

"Queridos hermanos: Glorificad en vuestros corazones a Cristo Señor y estad siempre prontos para dar razón de vuestra esperanza a todo el que os la pidiere; pero con mansedumbre y respeto y en buena conciencia, para que en aquello mismo en que sois calumniados queden confundidos los que denigran vuestra buena conducta en Cristo; que mejor es padecer haciendo el bien, si tal es la voluntad de Dios, que padecer haciendo el mal”,

Epístola de San Pedro 3,15-18

"Los grandes hombres no son sólo los grandes inventores, sino aquellos que cobraron conciencia de lo que era necesario hacer en un determinado momento de la historia"

Hegel.

\section{INTRODUCCIÓN}

Nuestra vida siempre debe ir más allá. Jesús de un mundo rural y galileo en torno al lago, le llegó la hora de presentar su mensaje en el centro del judaísmo en Jerusalén. Igual que Pablo de Tarso en Antioquía, le llegó la hora de la verdad de marcharse al areópago de Atenas. Todo el que ha hecho algo en la vida, puede dar razón de ella, mostrar su legitimidad o su falsedad, comentaba Platón. En el caso de Ratzinger, siempre hizo lo que no era de su gusto personal, renunciando a su investigación teológica, siendo difícil alcanzar una meta deseada (intelectualmente hablando). Uno, a veces no prepara nada, simplemente por convicción religiosa se deja llevar por Dios.

La fe no es una hoja de ruta, sino un camino ${ }^{1}$ a recorrer juntos, con espíritu de confianza. El elemento esencial para la Iglesia en camino es la valentía de la

1 Cf. En ese camino, la sabiduría es especialmente necesaria cuando las circunstancias son difíciles y las decisiones a tomar son menos evidentes. La Iglesia vivirá en un mundo siempre en evolución, según lugares y tiempos. Debemos discernir y comprender cuál es la voluntad de Dios. Cf. ( Ef 5, 10-17. Hechos 2) 
renuncia. También lo fue para la vida de Ratzinger durante toda su vida. Al igual que los primeros cristianos, él llega al coraje de la renuncia ${ }^{2}$, partiendo de la humildad de la escucha hacia su persona, hacia todos aquellos que estaban a su lado ${ }^{3}$ y siendo artesano de construcción. En muchos aspectos, no está sólo en juego el prestigio personal, sino la identidad religiosa.

Nacido en Marklt (Baviera, Alemania) el 16 de abril de 1927, en un sábado Santo y bautizado con el agua recién bendecida de la noche pascual, parecía indicar ciertamente, que iba a estar "predestinado". Su juventud estuvo marcada por muchos traslados, problemas políticos y gran pobreza. Junto a esto, sufrió el terror abominable de la guerra ${ }^{4}$.

A todo ello, tenemos que añadir las renuncias que forman parte de su vida, y que constituyen el estudio de este trabajo, en el que trato de contextualizarlas. No es fácil en principio hablar de ninguna de las realidades fundamentales de su pensamiento, aún cuando no podamos callar sobre ellas, por honestidad y deseo intelectual. No olvidemos que ha estado siempre bajo el paraguas de la opinión pública, y eso hace que se convierta en un personaje de la historia ${ }^{5}$.

De Dios decía Platón:

"Ardua tarea es descubrir el autor y al padre del cosmos, y, una vez que se ha descubierto, hablar de él a todos es hazaña poco menos que imposible" 6 .

Acercarse y excavar a la raíz del exponente teórico más cualificado del catolicismo actual, representa (si se me permite, en esta línea de ardua tarea, lo que no se podría nunca comparar) el mismo respeto y labor. Las palabras importantes en su teología y pensamiento son: Revelación, Fe, cristología, liturgia, escatología, eclesiología, liturgia, ecumenismo, la relación de Dios con otras religiones...etc.

El objetivo de este artículo no es estudiar los contenidos teológicos más importantes de J. Ratzinger. Como se indica en el título, se trata, más bien, de

2 "La vida es un aprendizaje de renunciamiento progresivo, de continua limitación de nuestras pretensiones, de nuestras fuerza..." Henry Frédéric Amiel.

3 Henry Wansbrough, trabajo con él, en la comisión bíblica pontificia. Sentía por él una admiración como persona y pensador. "Se preocupaba de conocer a todos los miembros, en la discusión escuchaba en silencio; era un oyente cuidadoso y flexible. Siempre tuvo la consideración de ser un tipo fiable". Cf. Henry Wansbrough, "La teología de J. Ratzinger", Revista de Libros, 130 (2007). 3-6.

4 Joseph Ratzinger, Mi vida. Recuerdos (1927-1977) (Madrid: Encuentro, 1997), 21-42.

5 Cf. Peter Seewald, Benedikt XVI - Ein Leben (Munchen: Droemer-Knaur, 2020) Es la última biografía escrita en alemán, dividida en seis partes y 74 capítulos. En primavera, verá su traducción al español. El primer capítulo comienza con el Karsamstag (Sábado Santo) y termina con el último, Der beginn einer neuen Ära (el comienzo de una nueva época)

6 Platón, Timeo, VI, $28 \mathrm{C}$. 
explicitar el aspecto más antropológico y humano de su propia persona ${ }^{7}$, en clave de renuncias. Una humanidad, que, en muchas ocasiones, pasa desapercibida o simplemente no es conocida a fondo. Aún así, su espíritu va a permanecer a lo largo de los años, como un legado de Verdad.

Mi exposición va a contar con dos partes: una primera, de acercamiento a la ausencia de renuncia hoy, con el valor que representa tomar una decisión importante. En segundo lugar, haré un elogio de las abdicaciones que considero más destacadas en la vida de J. Ratzinger-Benedicto XVI. La vida de renuncia está inscrita en su corazón.

\section{LA AUSENCIA DE RENUNCIA HOY.}

El secreto grande de los hombres es la renuncia (realizarla te permite ser una persona más valiosa). Es saber decir no a algunas cosas que se quieren, a cambio de enfocarse, de cuidar y defender otras que se quieren más. La persona de éxito es una persona de compromisos, pero también debe ser una persona de cambios profundos y renuncias ${ }^{8}$. Cada decisión implica una renuncia y a veces incluso duele.

El tema tiene una repercusión en la actualidad. Donde cuesta dejar cosas, hacer renuncias y salir de uno mismo. La persona tiene un deseo que es insaciable, para mantener lo mismo. Una persona está apegada cuando no es capaz de auto- regular su propia conducta. No es capaz de poner freno y tener autocontrol, como punto interno donde yo manejo mi vida, capaz de dirigir mi conducta de acuerdo con mis intereses vitales. Persistir en la conducta del apego es dañino para uno mismo y/o para los demás.

Sin embargo, cuando se tiene control interno, es que uno manda sobre sí, y que es capaz de decir no. Capaz de negarse, de revelarse ante determinadas cosas. Una persona que es capaz de romper el esquema de la normatividad y decide

7 A juicio de E. Biser, Catedrático jubilado de la universidad de Múnich: "Nunca ha buscado identificarse con el cargo. Siempre ha intentado seguir él mismo". Cf. Peter Seewald, Benedicto XVI. Una mirada cercana (Madrid: Palabra, 2006), 157.

8 Esto se produce a través de la metanoia, si entendemos que este cambio es radical y abarca la existencia entera de su extensión temporal. En opinión de Ratzinger, la metanoia lo que pide es un cambio del hombre con el fin de salvarse y no de un cambio del hombre que lleve como objetivo la idea de adaptación; un cristiano para cambiar debe hacerlo desde la profundidad de su ser. Cf, Francisco Vásquez, "La menesterosidad laical de una teología de los signos de los tiempos", Cuadernos de teología volumen 6/1 (2014): 7. 
que no lo va a hacer, porque no va con sus principios, y que atenta contra su conciencia:

"Un hombre de conciencia es el que al, precio de renunciar a la verdad, nunca compra el estar de acuerdo, el bienestar, el éxito, la consideración social y la aprobación de la opinión dominante" 9 .

El apego es la incapacidad de renunciar a un deseo, cuando debe de hacerse, por propia salud espiritual y por el bien de la Iglesia. El apego es lo opuesto al amor $^{10}$. Ratzinger, no tuvo dependencia ninguna y lejos de reorganizarse sistemáticamente, al no tener el objeto de deseo, se deja conducir por el Espíritu ${ }^{11}$.

$\mathrm{Su}$ reconocimiento de que le "faltan las fuerzas" induce a pensar a un mundo de "poderosos", casi de omnipotentes, en el que prácticamente nadie dimite, aunque tenga sobrados motivos para ello. Sus flaquezas, nos recuerdan que tenemos una cita ineludible con la finitud ${ }^{12}$, con los acabamientos definitivos. Nadie permanece para siempre.

Forma parte de la dimensión teológica y filosófica del teólogo bávaro, la búsqueda existencial del sentido de la vida, y una búsqueda de la verdad que trasciende el espacio privado de la mera subjetividad ${ }^{13}$. La renuncia siempre te hace libre. Produce en ti una libertad interior.

Es vivir según lo que somos y según lo que estamos llamados a ser, es decir, vivir en la verdad de ser hombre. El verdaderamente libre es capaz de renunciar

9 Benedicto XVI, Elogio de la conciencia (Madrid: Palabra, 2010), 22.

10 Cf. Benedicto XVI, Carta Encíclica sobre la caridad cristiana, Deus Caritas Est. Ramón Piñero, "El amor como relación. reflexiones sobre el amor en algunos escritos de J. Ratzinger", Cauriensia 2 (2007): 305-342; Joseph Ratzinger, Dios y el mundo Barcelona (Barcelona: Galaxia Gutenberg- Círculo de Lectores, 2002), 172: "Nuestra vida tiende en última instancia a descubrir el amor, a recibirlo y a darlo... Y el Cristo crucificado que representa el amor hasta el final, como Él mismo dice en el Evangelio según san Juan, convierte este principio en algo completamente real. Dios mismo es amor. En este sentido, el amor es la ley fundamental y el objetivo esencial de la vida."

11 "Conocer el amor de Cristo, que excede a todo conocimiento, para ser llenos de toda plenitud de Dios" ( Efesios, 19)

12 Pocas cosas son más directamente tangibles que la experiencia de la finitud del hombre. Teniendo en cuenta, la importancia de San Agustín, para el pensamiento de J. Ratzinger, señalo la reflexión que tiene el Obispo de Hipona sobre la finitud. Cf. Rafael Gómez, "Teología de la finitud y de la superación humanas", Scripta Teológica 15 (1972): 226. "Admisión de la finitud. Finitud intrínseca a la naturaleza humana, agravada por el pecado de origen. Exclusión de los remedios meramente humanos para colmar la limitación. La fe, como admisión y superación de la finitud. Permanencia, después de la fe, de la experiencia de la limitación, pero simultánea existencia de una prenda de la superación definitiva y eterna de ese estado precario".

13 "Pensar que se puede comprender la verdad esencial es visto ya como algo intolerante. Pero en realidad esta exclusión de la verdad es un tipo de intolerancia muy grave y reduce las cosas esenciales de la vida humana al subjetivismo" comentaba Ratzinger al presidir el congreso "Cristo: Camino, Verdad y Vida" en la Universidad Católica San Antonio de esa ciudad (UCAM) en el año 2002. 
a sí mismo para amar en el servicio. La verdad en este caso es que la acción personal se pone al servicio del bien de los demás, a lo que se subordina lo primero, y no al revés:

"En el ejercicio de su libertad, el hombre no puede olvidar que es un ser-de, ser-con y ser-para los demás. De ahí que deba asumir sus decisiones tomando en consideración a los demás y así, auto trascendiéndose, superar la tendencia egoísta de buscar exclusivamente su bien personal" ${ }^{14}$.

\section{EL VALOR DE UNA DECISIÓN}

"Seremos la toma de decisiones que tomemos"

El filósofo J. P. Sartre, del cual se cumplen 40 años de su muerte, ya nos decía que "estamos condenados a elegir". Y en la conciencia de esa elección está la levadura que propicia nuestra singularidad como humanos. No hay forma de saltar ese dilema, ya que siempre debemos elegir. Bien, es cierto, que en el caso del Papa teólogo en cada toma de decisión y en cada acto, nunca ha estado solo.

Es un tema complejo el de la toma de decisiones, aunque tienen un poder transformador cuando se analizan, se enseña bien su marco y te proyectan hacia algo origina $1^{15}$. Los que se arriesgan a decidir, se sienten mejor humana y espiritualmente con su vida. Aunque uno decidiendo, en alguna ocasión, no logra todo lo que se propone. Ya Aristóteles nos hablaba de la virtud moral para el discernimiento de lo justo:

"La justicia o las acciones justas son realizaciones del hombre virtuoso, o sea, del hombre que es amo y libre, el ciudadano que vive en, de y por la polis"16.

Ratzinger no improvisa nada, no agoniza ante decisiones simples, ni mucho menos cede ante cualquier presión. Nunca el temor fue un argumento de peso para él. Desde el principio tuvo confianza en su propia experiencia, desde sus

14 Cf. María Esther Gómez de Pedro, Libertad en Ratzinger. Riesgo y tarea (Madrid: Encuentro, 2014) ,95. En la misma línea, Cf. Benedicto XVI., Discurso a los Seminaristas de Roma, 20 de febrero de 2009. Si reducimos los bienes exclusivamente a los individuales, se restringe la idea de libertad que queda "desprovista de su verdad humana."

15 En palabras de un antiguo alumno suyo, hoy Cardenal y Patriarca de Venecia, Angelo Scola en la introducción a Ratzinger decía: "lo que sorprende cuando se tiene la oportunidad de escucharle y de dialogar con él sobre los temas más diversos, es que te comunica siempre un matiz más, algo nuevo, te abre siempre a algo que tú no habías visto antes." Cf. Ratzinger, Mi vida ..., 21.

16 Luis Garcés y Conrado Giraldo, "La justicia Aristotélica: Virtud moral para el discernimiento de lo justo", Indivisa: Boletín de estudios e investigación 14 (2014): 50. 
años de docente ${ }^{17}$. Siempre con su inteligencia soberana, claridad de palabra, primando el bien de la Iglesia por encima del suyo mismo, y que como en los años de la Congregación para la Doctrina de la Fe, las decisiones las tomaba conjuntamente, y teniendo presente a Dios. Nunca, su capacidad de decidir, estuvo determinada sólo por los sentimientos y la racionalización. El peso de la responsabilidad y la capacidad formidable para la acción teologal, fueron su sello de identidad.

Todo esto no fue nada fácil, porque el mundo se mueve de forma rápida, turbulenta, y esto hace que sea más complejo tomar resoluciones. Lo complejo de tomar decisiones y sentirse libre, resulta de la angustia que todos sentimos al tomarla; el desamparo que hace que las decisiones, aunque consultadas, son nuestras y solo nuestras. Por último, añadiendo la desesperanza ${ }^{18}$, de que esas decisiones no produzcan nuestros resultados o no sean entendidas en verdad.

La precisión en lo que se quiere decidir, lleva consigo también, la propensión a la acción. A veces la vida nos lleva tan rápido que no tenemos opción de pensar. El periodo de decisión, fue el del teólogo bávaro, meditado, no violento y preciso. Llevó la decisión a la práctica, sin que el miedo pueda paralizar. Incorporando cuales son las posibilidades que quiero, puedo y debo tomar. El valor de una idea buena, es tanto en cuanto es ejecutada, y siempre con la claridad de exposición, que Ratzinger presentaba ${ }^{19}$.

17 Como botón de muestra la lección que impartió en Bonn, con apenas 32 años hablando de un tema tan importante y transversal como el de Dios. En 1967 se dirigía no sólo a docentes, sino a todas las facultades de Tubinga. En un período complejo, donde por la fuerza se ocupaba la Universidad Católica de Milán y meses después llegaría el mayo francés, hablar de Dios era de una seguridad y valentía grande, que Ratzinger ya poseía.

18 En el caso de nuestro autor, la Esperanza y no la desesperanza, forma parte desde el principio en su pensamiento. Está bien arraigada. Cf. Benedicto XVI, Carta Encíclica sobre la esperanza cristiana, Spe Salvi (2007), En ella la esperanza tiene a Dios como contenido y motivo. Es decir, tiene una actitud teologal; Cf. Martín Gelbaert, "Una recepción teológica de la Spe Salvi”, Veritas 18 (2008): 38. En relación al ejercicio de la esperanza que es el actuar, comenta: "Toda actuación seria y recta es esperanza en acto, pues a través de nuestra actuación esperamos lograr algún proyectyo, solucionar algún problema, abrir puertas al futuro. Ahora bien, si sólo podemos esperar lo que es efectivamente posible con nuestros medios humanos, nuestra vida se ve avocada pronto a quedar sin esperanza."

19 No se trata, pues, de saber hablar, sino de saber decir cosas. Cf. René Descartes, Discurso del método para bien conducir la razón y buscar la verdad en las ciencias (Madrid: Trotta, 2018), parte $\mathrm{V}$ : "Pues es algo bien notorio que no hay hombres tan embrutecidos ni tan estúpidos, sin exceptuar siquiera a los insensatos, que no sean capaces de coordinar diversas palabras." 


\section{ELOGIOS DE RENUNCIAS}

\section{LA RENUNCIA A LA CÁTEDRA DE TEOLOGÍA EN LA PRESTIGIOSA UNIVER-} SIDAD DE TUBINGA

La época del 66-69 se torna, sabido por todos, complicada $^{20}$. En colaboración con H. Küng decide renunciar a Tubinga (1966- 69) y dirigirse (algunos hablan de refugiarse) a una Universidad recién fundada, sin renombre en el ámbito académico alemán, de provincias como Ratisbona (1968-77) ${ }^{21}$. Donde sólo puede empezar a realizar su síntesis teológica, porque es elegido arzobispo de Múnich por el Papa Pablo VI y tiene que dedicarse a su trabajo pastoral, es decir, "tirar del carro"22. Esta renuncia lleva un grado de humildad notable. Retirarse a un palacio de habitaciones frías en Múnich no debió de ser fácil.

Sin duda, como decíamos anteriormente, Tubinga era una de las más prestigiosas de Alemania y del mundo. Aquélla era en ese momento la mejor universidad alemana por doble razón: una porque había desaparecido Berlín, el polo prusiano de la cultura en la primera mitad del siglo XX; la otra porque hacia Múnich habían refluido los profesores de la antigua Breslau, una vez que la ciudad pasó a Polonia.

Su estancia en ella, se convertirá en la clave para entender el futuro. Hasta aquel momento el panorama teológico había estado determinado por la exégesis crítica, la investigación histórico-dogmática, la teología dialéctica y la teología litúrgica. Finalmente, prevalecía la lectura existencialista del Nuevo Testamento propuesta por Rudolf Bultmann siguiendo las categorías de Martin Heidegger.

20 Aún así, Ratzinger, tiene buen recuerdo de todo ese período de tiempo académico: Ratzinger se convierte en Catedrático de teología en Bonn, Münster, Tubinga y Ratisbona, aunque él cuenta, con especial simpatía sus primeros años de estudiante en teología, cuando daba clase en un lugar bastante pequeño, quedándose muchas veces sin sitio cuando llegabas tarde. Cf. Ratzinger, Mi vida..., 91-126. A pesar, de las convulsas jornadas, tenía tiempo para dedicarse a investigar. Aquí en Tubinga, vio la luz uno de sus primeros éxitos literarios, su comentario al Símbolo de Fe, Introducción al cristianismo

21 Cf. Pablo Blanco, "Fe, razón y amor. Los discursos de Ratisbona", Scripta Theologica 39 (2007):767-782. El discurso de Ratisbona el 12 de septiembre del año 2006 fue magistral. El teólogo bávaro vuelve a Ratisbona, esta vez ya como Papa. Sentía la necesidad de llevar a cabo ese discurso uniendo recuerdos y actualidad. La esencia de su teología encarnada en él, brotaba en palabras que relacionaban fe y razón. La razón serviría para evitar tiranías y eran útiles para la política y la democracia. Este discurso es el ejemplo de una larga serie de ellos. Las palabras pronunciadas en la ciudad bávara, suscitarán respuesta en todo el mundo. Fue comparado con la calidad de una Encíclica.

22 Un oso ha sido parte de su escudo de armas, desde su nombramiento como arzobispo de Múnich. Tiene su origen en un antiguo relato bávaro. Un oso devoró con gula el buey de un santo y como castigo fue castigado a tirar del carro santo hasta Roma. Ratzinger, se considero como un buey bueno y robusto para tirar del carro de Dios en este mundo. 
El teólogo Bávaro, se ve envuelto por una nueva atmósfera que lleva a cabo un vuelco de la universidad:

"Fue entonces cuando percibí cómo se iba infiltrando una tendencia nueva que -fanáticamente- se servía del cristianismo como instrumento para su ideología. (...) Fue entonces cuando realmente vi con claridad, e incluso experimenté, que el concepto inicial de reforma se corrompía. (...) Entonces comprendí perfectamente que, si se quería perseverar en la voluntad del Concilio, había que oponer resistencia a todos aquellos abusos" 23 .

Las nuevas estrellas son el marxismo y Ernst Bloch, con sus obras El principio esperanza (1954) y Ateísmo en el cristianismo (1973), que públicamente denigraba a Heidegger, ensalzaba a Marx y a Hegel, con reminiscencias profético-mesiánicas proponiendo una religión del éxodo y del reino, en la que el cristianismo aligerado de teología y cristología sería el agente de la revolución definitiva. Las agotadoras polémicas en el área intelectual de la facultad, le llevaron a renunciar y aceptar una nueva propuesta.

Tanto en sus años de teólogo, reseñados en esta primera renuncia, como en sus años de Pontificado, fue un gran intelectual. El hombre y Papa de la razón y la palabra, sin dejar al margen situaciones necesarias si eran concretas. Incluso en más de una ocasión afronta con éxito lo más práctico. Sin duda, la mejor defensa de la fe para él, había de ser racional.

Las palabras de este prólogo ${ }^{24}$, las últimas que ha escrito Ratzinger como profesor de Teología Dogmática, constituyen su "testamento" académico: "Con ello, con mi aceptación para servir como Obispo, acaba mi actividad docente..."

En plena tarea académica es sorprendido con el nombramiento de Arzobispo de Múnich y Frisinga en 1977, comenzando el camino episcopal, bajo su lema escogido de la tercera epístola de San Juan: "Colaborador de la Verdad". En este mismo año va a ser promovido Cardenal, en menos de un año de recibir su consagración episcopal.

23 Peter Seewald, La sal de la tierra. Cristianismo e Iglesia católica ante el nuevo milenio (Madrid: Palabra, 2005), 83-84.

24 "Cuanto más me ocupaba de las cuestiones, cuanto más penetraba en las fuentes, con tanta más fuerza se me desmoronaban las antítesis elaboradas y con tanta más claridad se veía la lógica interna de la tradición eclesial. Por consiguiente, el resultado que hoy presento, fruto de decenios de trabajo, se contrapone, pero al revés de entonces, a la opinión hoy corriente. Hoy estoy frente a la opinión general, pero en el mismo sentido inverso a como lo hice con mis primeros intentos. Y no es por espíritu de contradicción, sino porque el fondo mismo del problema me ha llevado a ello. No hace falta decir que también ahora precisamente es el nuevo quehacer el que determina mi visión de conjunto, al profundizarla y aclararla." 


\section{LA RENUNCIA DE ESCRIBIR UN GRAN LIBRO SISTEMÁTICO}

Ratzinger un par de meses antes de ser elegido Papa (aún sin saberlo) remitió una carta a Olegario González de Cardedal, tras la petición de este, a que el teólogo Bávaro viniese a España para impartir unas conferencias. Un párrafo de esa correspondencia personal manifestaba:

"He renunciado a dar conferencias. Los años que Dios todavía me dé, quiero consagrarlos a un libro de meditaciones sobre Cristo en la línea de lo que fue la gran obra de Guardini., El Señor" ${ }^{25}$.

La amistad con el teólogo español se remonta en el tiempo, pero, sobre todo, en los años de la Comisión Teológica Internacional. De él, González de Cardedal exclama: "Su trayectoria se reduce a un puro acto de servicio".

Las conferencias quedaron reducidas y esa gran teología sistemática que pretendía escribir, renunció a llevarla a cabo, al ser elegido Papa. Incluso su colega y amigo Olegario, sintió de manera cercana la renuncia de Ratzinger al declinarle su invitación de volver a España. ${ }^{26}$ Su permanente contacto con intelectuales y teólogos de todo el mundo ha sido su constante a lo largo de todos sus años.

\subsection{La renuncia a dar conferencias ${ }^{27}$}

El renunciar a dar conferencias, para él no fue fácil. Su deseo fue para siempre dedicarse a la teología. Siempre quiso dialogar y reflexionar en público delante de la Iglesia y de la humanidad. Atendiendo a la realidad sólo en la que piensa. Para él, el cristianismo es la religión del Logos (razón) ${ }^{28}$ y del Ágape (libertad)

25 Olegario González de Cardedal, año 2005.

26 Amistad que quedaba sellada intelectualmente hablando con la concesión del Premio Ratzinger de teología en el año 2011: "Creo que es el reconocimiento a una forma de vida entregada plenamente a la teología en la Iglesia y en la cultura pública. No he hecho otra cosa que, como sacerdote, ser teólogo, pero en esa complejidad de lo que es la teología en la universidad, en la Iglesia y en la sociedad" manifestaba el teólogo abulense. Cf. Entrega del "Premio Ratzinger" en su primera edición. Discurso del Santo Padre Benedicto XVI. Sala Clementina, jueves 30 de junio de 2011.

27 Cf. Joseph Ratzinger, Communio. Un programa teológico y eclesial (Madrid: Encuentro, 2013) En este volumen se compilan muchos artículos suyos. Se pueden encontrar bastantes conferencias desde los años 80, 90 y nuevo milenio. La perfecta organización cronológica de los artículos y la agrupación en epígrafes, facilita el trabajo para poder profundizar más en los textos.

28 Cf. Pablo Blanco, "La razón en el cristianismo: una reivindicación de Joseph Ratzinger", Scripta Theologica 37(2005): 643-660. La importancia de la razón, ha pasado intacta en su pontificado. 
Los discursos y conferencias son difíciles de agrupar por su gran extensión. La fe, que es un don de Dios posible a todo hombre, da que pensar ${ }^{29}$, es un dinamismo $^{30}$ que no era sencilla de parar intelectualmente, para el teólogo alemán. Siempre, no desde el intento de crear un sistema propio, una teología individual; sino como él de forma continuada manifestaba y pensaba, en comunión con la fe de la Iglesia:

"La Iglesia no existe para sí misma, sino para la humanidad. Existe para que el mundo llegue a ser un espacio para la presencia de Dios, espacio de alianza entre Dios y los hombres...Ella existe para que pueda darse la alianza en la que Dios regala su amor y obtiene una respuesta de amor". 31

\subsection{La renuncia a escribir una obra sistemática en la línea excelsa de Guardini}

Dentro de sus años de estudio, varias personas influyeron en su formación: Schmaus, Maier, Pescher, Guardini... En cuanto al aporte de teólogos, Ratzinger comenta: "No he vuelto a conocer hombres con una formación cultural y teológica como Lubac y Balthasar" 32 donde desarrolla un capítulo sobre sus estudios de teología en Múnich.

Bajo el paraguas de una amistad profunda ${ }^{33}$, hay un singular entrecruzamiento de destinos (uno llegará a Papa, el otro renunciará al cardenalato) y

29 No es sólo cuestión para comprenderla desde la inteligencia, sino desde la verdad, la voluntad, el bien y los fines que dan sentido a la existencia humana.

30 Así lo manifestaba ya el argumento ontológico de San Anselmo. Cf. Edualdo Forment, Historia de la filosofía. II Medieval (Madrid: Palabra, 2004), 72.

31 Joseph Ratzinger, "La iglesia en el umbral del tercer milenio", Revista Académica e Institucional Páginas de la UCP 98 (2015):127.” Joseph Ratzinger, “¿Por qué pertenezco a la iglesia?”, Revista Académica e Institucional, Páginas de la UCP 89 (2011): 86: "Si yo estoy en la Iglesia es por las mismas razones porque soy cristiano. No se puede creer en solitario. La fe sólo es posible en comunión con otros creyentes. La fe, por su misma naturaleza, es fuerza que une. Esta fe o es eclesial o no es tal fe." Cf. Joseph Ratzinger, Teoría de los principios teológicos. Materiales para una teología fundamental (Barcelona: Herder, 1985), 24.

32 Ratzinger. Mi vida ..., 59-72. Donde desarrolla un capítulo de sus años de estudio en Múnich. En la homilía pronunciada por el cardenal Ratzinger en el funeral de Hans Urs Von Balthasar en 1988 comentaba de él: "Hay una frase de San Agustín que expresa muy bien lo que lo que Balthasar pretendía: Toda nuestra obra en esta vida, queridos hermanos, consiste en curar los ojos del corazón para que puedan ver a Dios. Lo que en realidad le interesó fue la curación de los ojos del corazón para poder percibir lo verdadero"

33 Con apenas 20 años lo lee y escucha aquél a quien él no dudó en elegir como un gran "maestro" Ya como Papa, en el viaje a Verona, el 19 de octubre de 2006, salió a la luz un "encuentro" particular entre los dos. En efecto, no se puede olvidar que Verona es la ciudad en la que nació Guardini el 17 de febrero de 1885. Profundamente conmovido, el Papa recibió como regalo precisamente en Verona una copia del acta bautismal de Guardini. 
ciudades (Múnich y Roma) entre Romano Guardini y Joseph Ratzinger. Ambos realizaron caminos muy paralelos, diferenciados, pero extraordinariamente intensos en buscar lo esencial al cristianismo ante la provocación de Feuerbach; sus preocupaciones por la Iglesia, por el futuro de una Europa que tiende a repudiar su pasado y la pasión por la liturgia. En relación con esta última, lograron potenciar su belleza, su riqueza oculta en su forma esencial y su grandeza en el tiempo.

Para el teólogo veronés, un conocimiento teológico constructivo no puede realizarse nunca cuando la Iglesia y el dogma aparecen solamente "como límite y cierre". El dogma se convertía así en el ordenamiento fecundo del pensamiento teológico sin olvidar la reflexión y la experiencia. Guardini buscaba en palabras de Ratzinger: "un nuevo avance hacia el ser mismo, la preocupación por lo esencial que se encuentra en la verdad".

Guardini supo pasar del positivismo y la fenomenología a la mirada teológica. A este respecto, con lenguaje sencillo y en profundidad, resulta muy ilustrativo el texto siguiente:

"Acogimos con gratitud la liberación que producía la seriedad con la que nuestro maestro buscaba la verdad. Comprendimos que la crítica era necesaria en esa búsqueda de la verdad. Pero reconocimos también que dicha crítica existía en Koch al nivel menos importante y faltaba en el más importante. Ciertamente era importante plantear cuestiones históricas, psicológicas y de crítica textual para distinguir lo verdadero de lo falso, pero la tarea fundamental de la crítica teológica debía consistir en el distinguir la esencia del conocimiento teológico creyente de la de las otras formas de conocimiento y de ciencia; en fundamentar este conocimiento a partir de su auténtica fuente, en fijar sus criterios normativos y extraer todas las consecuencias de su esencia. Nosotros descubrimos la revelación como el "hecho originante" del conocimiento teológico, la Iglesia como su portadora y el dogma como ordenación del pensamiento teológico...,

Nadie, en el mundo de la teología y en la Iglesia, cuestiona la calidad intelectual máxima que J. Ratzinger-Benedicto XVI atesora. Su desarrollo orgánico en sus pensamientos relacionados con temas importantes como la búsqueda de la verdad, el coraje de la razón, la fe o el amor verdadero, constituían un

34 Romano Guardini, Apuntes para una biografia (Madrid: Encuentro, 1945), 122-123. El subrayado que es mío, indica las tareas fundamentales de la teología. Cf. Th. Haeker, Christentum und Kultur (München: Kösel, 1946). en su reflexión sobre la fenomenología (y sus debilidades) en M. Scheler. También resulta interesante leer el último capítulo de John Henry Newman, Apología pro vita sua (Madrid: Encuentro, 2010) donde aborda este tema. 
itinerario intelectual de viaje teológico. Con la visión de un Concilio Vaticano II y una síntesis madura, el teólogo Bávaro tenía las coordenadas para poder llegar a la realización de una gran obra sistemática ${ }^{35}$.

\section{LA RENUNCIA A SU PAÍS NATAL PARA SERVIR A JUAN PABLO II HASTA EL} FINAL

"Dejar la enseñanza universitaria, dejar esta comunión estimulante con los jóvenes, dejar la gran liza intelectual para conocer e interpretar el misterio de la criatura humana, para hacer presente en el mundo de hoy la interpretación cristiana de nuestro ser, todo aquello debía parecerle como un perderse a sí mismo, perder aquello que constituía la identidad humana de ese joven sacerdote. Sígueme, Karol Wojtyla aceptó, escuchando en la llamada de la Iglesia la voz de Cristo. Y así se dio cuenta de cuanto es verdadera la palabra del Señor: «Quien pretenda guardar su vida la perderá; y quien la pierda la conservará viva». Nuestro Papa — todos lo sabemos - no quiso nunca salvar su propia vida, tenerla para sí; quiso entregarse sin reservas, hasta el último momento, por Cristo y por nosotros" ${ }^{\prime 3}$.

Estas palabras proclamadas manifiestan también lo que sería su vida. La relación con Juan Pablo II estuvo siempre caracterizada por amistad y afecto ${ }^{37}$, impresionándole su relación con Dios basada en la intensidad de su oración y unida fuertemente a la Iglesia. Juan Pablo II lo nombró prefecto para la Congregación de la Doctrina de la Fe en $1981 .^{38}$ Lo mismo, que en sus años finales

35 Cf. Pablo Blanco, "Reseña al libro La teología de Joseph Ratzinger. Una introducción", Teología y Vida 52 (2011): 738-740.

36 J. Ratzinger en la homilía de la Misa de exequias de Juan Pablo II, el 8 de abril de 2015. Justo un dia antes de su muerte pronunciaría su discurso en Subineo el 1 de abril. Constituía el desafío que lanzaba al agnosticismo y laicismo dominante en la cultura europea.

37 Joseph Ratzinger, Juan Pablo II: Un Papa entre dos milenios (Barcelona: Lumen, 2000). En este libro se pone de manifiesto la voz de un amigo y compañero del Papa. Wlodzimierz Redzioc, Junto a Juan Pablo II: Sus amigos y colaboradores nos hablan de él (Madrid: Ares, 2014). En la primera entrevista, de las 21 que hay, se recoge algunos testimonios: "El primer encuentro consciente que tuve con el cardenal Wojtyla fue en el cónclave en el que fue elegido Juan Pablo I. Durante el Concilio, habíamos colaborado ambos en la Constitución sobre la Iglesia en el mundo contemporáneo, sin embargo, fue en secciones diferentes, por lo que no nos habíamos visto...Wojtyla, había leído mi Introducción al Cristianismo, que había citado también en los ejercicios espirituales predicados por él a Pablo VI y la Curia, en la Cuaresma de 1976. Por eso era como si interiormente ambos esperásemos encontrarnos". "Sentí desde el inicio una gran veneración y una simpatía cordial por el metropolitano de Cracovia. En el pre-cónclave de 1978 el cardenal Wojtyla analizó para nosotros de forma asombrosa la naturaleza del marxismo."

38 Difícil, y reconocido papel, el de ser Prefecto durante 24 años. En su día, W. Pannenberg mostró su tristeza cuando Ratzinger fue nombrado prefecto de la Congregación para la Doctrina de la Fe: "Él era el teólogo", dijo, "con quien yo hubiera querido pensar el evangelio, reflexionando sobre 
Juan Pablo II había mostrado su voluntad de permanecer fiel a su misión en medio del dolor y de la enfermedad hasta concluir; con igual fidelidad, continuó sus años junto a él (Hay quien haciendo paralelismos erróneos interpretó su renuncia como una cobardía)

Desde su nombramiento, por parte de Juan Pablo II, como prefecto de la Congregación para la Doctrina de la Fe fueron apareciendo nuevos libros de Ratzinger. Hay dos esenciales. El primero es su Escatología (1977), que él considera su libro más elaborado y que abre el horizonte de la historia a su último sentido. La pregunta por el fundamento, consistencia y destinación de la libertad humana, por la verdad y consumación de la persona, por la vida, la muerte y el futuro aparece aquí expuesta desde la perspectiva cristiana, sobre el trasfondo de movimientos como el marxismo, las visiones revolucionarias de los grupos utópicos y la teología de la liberación.

La segunda obra clave de este decenio es Teoría de los principios teológicos (1982), que trata de pensar los fundamentos del existir cristiano: relación entre la estructura y el contenido de la fe; principios formales del catolicismo; problemas claves en el diálogo ecuménico; principios estructurales de la teología y su ámbito antropológico. La fase final de su pensamiento se centra en el diálogo con el pensamiento débil de la posmodernidad, nacido tras el ocaso de Marx y la aparición de Nietzsche y para el cual el ser, la verdad, el deber y la culpa carecen de fundamento una vez que Dios ha muerto.

Desde este enclave académico, según Benedicto XVI, los autores más influyentes del mundo de la filosofía en el Papa Juan Pablo II fueron: un manual de introducción a la metafísica, donde trató de comprender la relación entre concepto y experiencia, lo que pudo conseguir en unos meses de duro esfuerzo. Después descubrió a Max Scheler y la fenomenología. Afirma Benedicto XVI:

"Esta precisión del ver, esta inteligencia del hombre no a partir de abstracciones y de principios teológicos, sino tratando de captar su realidad en el amor, fue y siguió siendo decisiva para el pensamiento del Papa". Más tarde le influye San Juan de la Cruz, quien le abrió al mundo interior "del alma y de la gracia" 39 .

Sus propuestas pontificias, por lo tanto, son similares en relación con temas como la juventud, el diálogo con el mundo y la cultura, la racionalización de la

la cercanía y diferencia en nuestra comprensión del cristianismo" Quizás, Pannenberg fuera el que más sintiera su renuncia académica.

39 Benedicto XVI, Juan Pablo II mi amado predecesor (Madrid: San Pablo, 2007). 
fe, el progreso basado en la justicia y en la solidaridad hacia una nueva evangelización.

En el año 2003, un periodista de la EWTN le formulaba una pregunta a J. Ratzinger, en su mismo despacho de la Santa Sede, donde se vislumbra ya su deseo de querer retirarse en 1991 y que manifiesta la unión que tenía con Juan Pablo II:

"Usted ha estado en este puesto 21 años y según he leído en artículos, quiso retirarse varias veces, ¿Porqué todavía está aquí? El teólogo Cardenal le contestaba: quise retirarme en el 91, 96 y 2006 porque quería escribir libros y volver a mis estudios como hizo el Cardenal Martini. Pero viendo como el Papa sufría no podía decirle "yo me retiro, quiero escribir libros" Viéndolo a él y tal como él me dijo, yo tenía que continuar".

No se entendería el Pontificado de Juan Pablo II sin J. Ratzinger, tal como acredita toda la documentación a la que estaba al frente el teólogo Bávaro. Es más, en palabras del Dr. Pablo Blanco ${ }^{40}$, en una entrevista realizada comentaba:

"Cuando San Juan Pablo II iba a viajar por todo el mundo, era Ratzinger quien se "quedaba en la tienda" Cada uno supo estar en su sitio y ambos se complementaron mutuamente".

Por lo tanto, la relación que tenían era más sencilla de llevar, que interpretar algunas partes de la lectura de la Veritatis Splendor. Texto, que parece haber salido directamente del corazón de Juan Pablo II y que Ratzinger siempre consideró como fundamental a la hora de tener un acercamiento a él. La crisis cultural, moral y religiosa que el marxismo introduce en occidente y el abrigo a la Iglesia en los ideales proféticos del Vaticano II, son las coordenadas para entender el trasfondo de ambas elecciones papales. Sin duda, el Vaticano II los unió.

H. de Lubac y Balthasar fueron referencias fundamentales para Juan Pablo $\mathrm{II}^{41}$ y lo son igualmente para Ratzinger. Por lo tanto, el suelo vital que arraigan en pensamientos, hizo que la posible renuncia de Ratzinger, en pro a determinadas cuestiones académicas y personales, quedara relegada por el compromiso que les unía.

40 El teólogo, en su entraña personal, Pablo Blanco (anteriormente citado) ha estudiado a fondo el pensamiento de J. Ratzinger-Benedicto XVI. Sus artículos, reseñas, colaboraciones en obras colectivas y publicaciones son extensísimas y de alta calidad teológica. Como botón de muestra: $L a$ teología de Joseph Ratzinger. Una introducción (Madrid: Palabra, 2011), Benedicto XVI habla sobre cultura y sociedad (Madrid, Palabra, 2013), Joseph Ratzinger, Benedicto XVI: un mapa de sus ideas (Madrid: BAC, 2012), Benedicto XVI: el Papa alemán (Barcelona: Planeta, 2010).

41 No quiere decir que fueran los únicos. También se nutrió de San Juan de la Cruz y M. Scheler con la fenomenología y el personalismo. 
En conclusión, Benedicto XVI ha escrito:

"Mi recuerdo de Juan Pablo II está lleno de gratitud. No podía y no debía intentar imitarlo, pero intento llevar adelante su herencia y su tarea lo mejor que he podido Y por eso estoy seguro que todavía hoy su bondad me acompaña y su bondad me protege".

\section{LA RENUNCIA PAPAL}

Sorprende la puntualidad "alemana" de su renuncia: el 28 de febrero a las $20,00 \mathrm{~h}$ de la tarde. Como sorprendente fue que, un intelectual y teólogo de semejante brillantez, llegara a la Cátedra de Pedro. ${ }^{42}$ Ya el 11 de febrero de 2013, Benedicto XVI, casi al concluir el octavo año de su pontificado, anunció su voluntad de dejar el ministerio petrino a finales de ese mes con serenidad ${ }^{43}$ y plena libertad, porque ya no se sentía capaz de llevar con vigor, física y espiritualmente, el peso del pontificado. Es decir, una aceptación de los hechos. El día 28 en torno a las 17:00h partiría hacia Castengandolfo. Estas fueron sus palabras previas:

"Siendo muy consciente de este acto, con plena libertad, declaro que renuncio al ministerio de Obispo de Roma. Para gobernar la sede de Pedro y anunciar el Evangelio, es necesario tener tanto del vigor del cuerpo como del espíritu, vigor que, en los últimos meses, ha disminuido en mi de tal forma que tengo que reconocer mi incapacidad, para ejercer bien el ministerio que me fue encomendado".

No podemos olvidar que vivimos en un mundo sujeto a rápidas transformaciones y sacudido por cuestiones de gran relieve para la vida de la fe, para llevar a cabo un pontificado y anunciar el evangelio. El peso de un ministerio que en el último siglo había cambiado profundamente en la modalidad de su ejercicio, con el conglomerado de celebraciones, compromisos, nombramientos y viajes internacionales

42 Cf. Así lo recogía el profesor de teología protestante en la Universidad de Múnich, en el Frankfurter Allgemeine Zeitung (21-4-2005) El profesor alemán nunca se quitó el birrete académico para acceder al solideo pontificio.

43 Cf. Alfred Sonnenfeld, Serenidad. La sabiduria del gobernarse (Madrid: Rialp, 2018) Ciertamente Ratzinger-Benedicto XVI encarnó la eudaimonía aristotélica. Esa con la que cuenta el hombre para no estar en el mundo a la merced del azar. Es la más excelente, por ser estable, personal y elegida en referencia a lo que es mejor para sí y para los demás. Cf. Adriana Romero, "La concepción aristotélica de la eudaimonía en Ética a Nicómano. Relación entre vida activa y vida teorética", Revista de Investigación 85 (2005): 13-30. 
Lo hizo en latín. 598 años de la anterior renuncia a un papado ${ }^{44}$. Cada Cardenal reaccionó de manera distinta. No fue un pontificado fácil, ninguno lo es ${ }^{45}$. En su caso, en algún momento incluso, él quiso complicarse la vida conscientemente (como el inicio de encuentros con las víctimas de los abusos). Nunca buscó ser electo o mostrarse ávido de poder ${ }^{46}$.

Desde mi punto vista, no hablo de fracaso en su renuncia, sino de una decisión responsable (conciencia de responsabilidad ante el cargo). No se trata de abandonar, sino de actuar con responsabilidad. La renuncia es un aporte. Es un hombre que entregó un Tesoro y consideraba que había que mantenerlo vivo (Dios como Live-Antwort, respuesta viva). Lo cierto es que es un argumento más de razón que de fe, pero la fe no dice nada sobre la duración de los pontificados. En esta línea, también hay muchos teólogos, filósofos y cardenales que ven esta renuncia como un enaltecimiento:

"Con su gesto, Benedicto XVI ha quedado investido de la autoridad del "testimonio", la que Jesús de Nazaret más elogió" ${ }^{47}$.

44 El eremita Pedro Morrone, en los montes cercanos a Castelsangro y con fama de santidad, fue coronado Papa en 1294 con el nombre de Celestino V; pero revestido su corazón de gran humildad y desprendimiento, hizo que al poco tiempo renunciase al pontificado. nacido en el seno de una familia numerosa, entre los principios cristianos de unos padres buenos: «Ambos eran justos a los ojos de Dios y muy alabados por los hombres; daban limosna y acogían a los pobres de muy buena gana en su casa. Tuvieron doce hijos, a semejanza del patriarca Jacob, y siempre pedían al Señor que alguno de ellos sirviese a Dios» Excéntrico, extremadamente sencillo, basto en las cosas humanas, y desconocedor de los asuntos de gobierno... son algunos de los datos que leemos en su autobiografía. Su elección tuvo lugar en un contexto de luchas, donde se elige a un monje de vida eremítica, apenas sin formación teológica, que no sabía latín (por primera vez se tiene que usar la lengua vulgar en la corte pontificia) y sin capacidad para gobernar. La renuncia era inevitable. Otros, interpretan su renuncia, a su corazón revestido de gran humildad y desprendimiento. La humildad es convicción, de la mente abierta a todo, es sinceridad y modo, el medio para alcanzarla. ¿Fue el suyo un gesto de humildad o de cobardía? La renuncia de Benedicto XVI es completamente diferente a la de Celestino V. Cf. Olegario González, "Los vuelcos en la Iglesia de Ratzinger a Bergoglio", Veritas 30 (2014): 129-161.

45 Pablo Blanco lo resumió en 7 palabras: Razón, comunión, creación, (ad) oración, Jesucristo, Iglesia, Belleza. Cf. Pablo Blanco, "Benedicto XVI ¿Un pensador postmoderno? El pensamiento de J. Ratzinger", Revista Interdisciplinaria de filosofia y psicología 29 (2014): 29-43.

46 La película "Los dos papas" de Netfix (2019) trata de desvirtuar el momento del cónclave, presentándolo como un personaje lleno de poder. En una escena de la película mientras desayunan los cardenales, uno de ellos, citando a Platón dice "que el requisito más importante de cualquier líder es no querer ser líder", a lo que un interlocutor añade: "Por eso no debe de ser Ratzinger, él en verdad lo desea. Repetir clichés que ya están abandonados y que no se corresponde con su figura. Cf. Andrea Monda, La humildad de Benedicto. Sus virtudes como Papa (Madrid: Cristiandad , 2013) "Sólo la humildad puede encontrar la Verdad y la Verdad a su vez es el fundamento del Amor, del que últimamente todo depende ": así lo escribía el Papa Benedicto XVI en el mensaje de saludo con ocasión del $50^{\circ}$ aniversario de la creación de la Comisión Teológica Internacional (22 octubre 2019)

47 Manuel Fraijó, en el Diario El País, 12 Febrero 2013. 
Esta renuncia, no es una más, encerrando unas enseñanzas teológicas, en regla con el código de derecho canónico, que han sido recogidas por Alfonso Carrasco Rouco ${ }^{48}$. Lo cierto, es que el acto cumplido en su renuncia por el Papa Benedicto XVI, puede situarse en continuidad con el Magisterio ${ }^{49}$ de los dos últimos Concilios.

La abdicación es un gesto decisivo que muestra la conciencia de su ser, servidor en la viña del Señor ${ }^{50}$, alguien llamado a poner toda la propia persona al servicio de su misión, a favor de la Iglesia Universal. La renuncia pone de manifiesto el descentramiento con respecto a su propia persona, hacia Jesucristo, verdadero Pastor supremo ${ }^{51}$.

\section{CONCLUSIÓN}

Por el bien de la misión, para anunciar a cualquiera, de manera transparente y creíble en nuestro tiempo, que Dios es amor, debemos de abandonar todo tipo de convicción y seguridad. La valentía de dejar, lo que muchos desafortunadamente, no están dispuestos ${ }^{52}$. También nosotros necesitamos redescubrir juntos la belleza de la renuncia, sabiendo que acarrea sufrimiento e incomprensión en más de una ocasión, como así fue en la vida de J. Ratzinger-Benedicto XVI:

"El que cree en Dios, en el Dios que precisamente en las apariencias alteradas de Cristo crucificado se manifestó como amor "hasta el final" ( $J n$ 13,1), sabe que la belleza es verdad y que la verdad es belleza, pero en el Cristo sufriente

48 Alfonso Carrasco, "La renuncia al Misterio Petrino. Notas teológicas", Scripta Theologica 45 (2013): 467-475. "El primado no es un sacramento, sino una misión para con la Iglesia universal, una participación en la que le ha sido confiada por Cristo a Pedro y sus sucesores" (470) "Los dones recibidos con el Primado no se hacen algo propio de la persona privada, que no entra tampoco en posesión de cualidades nuevas"(470) "El Primado proviene de la promesa de Cristo a Pedro y a sus sucesores, que reciben un particular don del Espíritu, éste, sin embargo, por su misma naturaleza, le es dado a la persona sólo al servicio de su relación con la Iglesia Universal" (472) "Y en la medida en que la persona pondría así en juego libre y conscientemente todos sus haberes y todo su ser para hacer posible una mejor realización de la misión propia del sucesor de Pedro, no cabría tampoco el reproche de haber abandonado la tarea encomendada por el Señor (473)"

49 Tarea poco fácil tras el aplastamiento de lecturas reductivas y clichés prefabricados incapaces de valorizar la riqueza, complejidad y fidelidad a las enseñanzas de este último Concilio Vaticano II.

50 Joseph Ratzinger, La fraternidad de los cristianos (Salamanca: Sígueme,2004), 16: "Cuando Dios llama -y la Iglesia es convocación de Dios- piensa en el servicio a los demás. No elige para honrar a los elegidos ni para romper la comunidad humana. Llama para cumplir una misión que implica sufrimiento y que se concreta en el amor generoso y servicial".

51 Cf. Spe Salvi, n' 14 : "La salvación es una realidad comunitaria, presupone dejar de estar encerrados en el propio yo"

52 "Pero las preocupaciones del mundo, la seducción de las riquezas y las demás concupiscencias les invaden y ahogan la Palabra, y queda sin fruto" (Mc 4,19) 
comprende también que la belleza de la verdad incluye la ofensa, el dolor e incluso el oscuro misterio de la muerte, y que sólo se puede encontrar la belleza aceptando el dolor y no ignorándolo." 53

San Pedro dice que el Señor "purificó los corazones con la fe"

Dios purifica, Dios simplifica, a menudo hace crecer quitando, no añadiendo, como haríamos nosotros. La verdadera fe purifica de los apegos. Para seguir al Señor se necesita caminar ágiles y para hacerlo se requiere aligerarse, aún así nos cuesta. Salir de sí es la reforma fundamental.

Cuando uno tiene la oportunidad de acercarse a este teólogo-Papa, descubre aparte, de que la necesidad del cristianismo debe tener pretensión de verdad (hilo de oro en el pensamiento de nuestro autor) es que la misma, nunca se afirmará desde el poder vulgar, sino desde la potencia que el servicio, el testimonio, la proclamación y la discusión llevan consigo. La virtud, sólo de personas excepcionales, de hacer fácil lo difícil. Así lo reconoció la gente que llenaba la plaza de San Pedro en su último ángelus, encarnando el agradecimiento de todo un pueblo de Dios.

"Soy simplemente un peregrino que comienza la última etapa en su peregrinaje en esta tierra" fueron sus últimas palabras en Castengandolfo. ${ }^{55}$

Destaco como, en medio de todas las dificultades que ha tenido y las afirmaciones que ha recibido (Cardenal de hierro, inquisidor cerrado, el azote de la teología de la liberación...) ha sabido hacer en cada momento lo que era importante, seguir laboriosamente su camino de renuncias (que al final en palabras del Dr. Pablo Blanco, “enriquecen más su pensamiento, dándole profundidad y realismo”) de hacer entender y expresar en términos inteligibles, el camino de la Iglesia $^{56}$. Ha sido coherente con su vida, se retira para abandonar el gobierno de la Iglesia, deja hacer y termina sus días en paz.

53 Esta belleza de renuncia, a veces, acarreó sufrimiento e incomprensión en más de una ocasión para el teólogo y Papa Emérito Benedicto XVI. Cf. Joseph Ratzinger, "La contemplación de la belleza", Humanitas: revista de antropología y cultura cristiana, 29 (2003): 8-10.

$54($ Hch 15, 9)

55 "El alma liberada de las ataduras terrestes se eleva a las alturas, dejando las cosas inferiores. Como nada que venga de lo alto interrumpe su deseo, el alma es atraída por el Bien hacia lo que está por delante, como dice el Apóstol, y su vuelo la conducirá más arriba. Tiene el deseo de no renunciar, por lo ya adquirido, a las cumbres que están por delante, que le comunican un movimiento de ascensión en el que encuentra siempre nuevo aliento para volar más alto"(Gregorio de Nisa) Cf. Michel Fédou., "La vida cristiana, un éxodo. El testimonio de los padres de la Iglesia", Selecciones de Teología 253 (2017) :132-133.

56 Amor a la Iglesia como impulso al gesto de su renuncia. 
Al final de la Critica de la Razón Pura ${ }^{57}$, Kant comentaba que, sería una injusticia que, de los fines esenciales de la vida humana, unos estuvieran más dotados que otros. En relación con cuestiones de sentido, Verdad y Salvación. Salvación y Verdad que ya abraza en gozosa esperanza, con sabiduría teológica y profunda gratitud, el Papa Emérito Benedicto XVI.

Con su lema espiritual: "Colaborador de la verdad", caminó por la ciudad eterna, sirviendo como Cardenal, prefecto de la Congregación para la Doctrina de la Fe y Papa. Como él mismo dice: "Como una bestia de carga, sabiendo que asi estoy contigo ${ }^{, 58}$.

El Mozart de la teología ${ }^{59}$, aceptó servir a la Iglesia: "No cedáis a la lógica del interés egoista" predicaba Benedicto XVI. Estad: "Al servicio del bien común y la Verdad" con un magisterio luminoso, en un tiempo, el de hoy, de ausencia en cultura crítica.

Ratzinger no es, creo, de los que renunciaba al poder para seguirlo ejerciendo en la sombra: "Gracias de corazón y pido perdón a Dios por mis errores" (día 28 de febrero 2013, cuando puso renuncia a su pontificado) Aún resuena la autoridad de su argumentación. Retirado para rezar, ya su corazón y su mirada se abren confiadas a Dios (así, lo refería Papa Francisco en el 65 aniversario del inicio de su vida de servicio a la Iglesia Católica) al que invocamos como nuestro Futuro Absoluto. Los últimos días de su vida, son como las últimas palabras de la Biblia, una oración ${ }^{60}$. Un itinerario hacia Dios, esta vez sin renuncia alguna.

Como expresa en la segunda Encíclica que escribió en el 2007, con una enorme esperanza para el presente y futuro inmediato:

"Que el amor pueda llegar hasta el más allá...en el que estemos unidos unos con otros con vínculos de afecto más allá del confín de la muerte, ha sido la

57 Cf. Jean Grondin, "La conclusión de la Crítica de la Razón Pura", Universitas philosophica, 49 (2007):13-32. Miguel García-Baró, Kant y herederos. Introducción a la historia de la filosofía occidental (Salamanca: Sígueme, 2019), 22-41.

58 Ratzinger, Mi vida,133.

59 Conviene señalar que a lo largo de toda la vida de Ratzinger, la dimensión estética formaba parte de su pensamiento y de su visión de la vida. Un ejemplo de ello, es su temprana afición a la música. La profundidad de sus ideas, hacen que reciba el nombre del genio y compositor nacido en Viena.

60 Joseph Ratzinger-Benedicto XVI, Jesús de Nazaret (Madrid: Encuentro, 2011): "La oración no ha de ser una exhibición antes los hombres, requiere esa discrección que es esencial en una relación de Amor". Javier Prades, "El misterio de Dios contemplado y vivido por J. Ratzinger", Communio 7 (2007): 90-91 Dirigirse a Dios como nuestro Padre: la oración. Sólo una oración verdadera, de petición y de adoración, puede rescatar al cristiano. La fe cristiana, llega a decir Ratzinger, es la explicación de la oración de Jesús, del Hijo único del Padre, en quien se desvela el significado de toda oración cristiana. Cf. Manfred Schlosser., Teología de la oración (Salamanca: Sígueme, 2018), 11-20: "La oración cristiana consiste en la elevación de los corazones (mentes) a Dios (San Agustín, San Juan Damasceno) Lo cual involucra a la fe, la revelación y a Dios" 
convicción fundamental del cristianismo de todos los siglos y sigue siendo también hoy una experiencia consoladora" 61

\section{REFERENCIAS BIBLIOGRÁFICAS}

Benedicto XVI - Joseph Ratzinger. Jesús de Nazaret. Madrid: Encuentro, 2011. - Leyendo la Biblia con el Papa Francisco. Madrid: Cristiandad, 2018.

-. Juan Pablo II mi amado predecesor. Madrid: San Pablo, 2007.

-. Discurso a los Seminaristas de Roma, 20 de febrero de 2009.

- Entrega del "Premio Ratzinger". En su primera edición. Discurso del Santo Padre Benedicto XVI. Sala Clementina, jueves 30 de junio de 2011.

-. Elogio de la conciencia. Madrid: Palabra, 2010.

-. Carta Encíclica sobre la esperanza cristiana, Spe Salvi ,2007.

Blanco, Pablo. "Fe, razón y amor. Los discursos de Ratisbona". Scripta Theologica 39 (2007): 767-782.

- "La razón en el cristianismo: una reivindicación de Joseph Ratzinger". Scripta Theologica 37(2005): 643-659.

—. "Reseña al libro La teología de Joseph Ratzinger. Una introducción". Teología y Vida 52 (2011): 738-740.

Carrasco, Alfonso. "La renuncia al Misterio Petrino. Notas teológicas". Scripta Theologica 45 (2013): 467-475.

Descartes, René. Discurso del método para bien conducir la razón y buscar la verdad en las ciencias. Madrid: Trotta, 2018.

Fédou, Michel. "La vida cristiana, un éxodo. El testimonio de los padres de la Iglesia". Selecciones de Teología 253 (2017) :131-135.

Forment, Edualdo. Historia de la filosofía. II Medieval. Madrid: Palabra, 2004. Fraijó, Manuel. Diario El País, 12 febrero 2013.

Garcés, Luis y Giraldo, Conrado. "La justicia Aristotélica: Virtud moral para el discernimiento de lo justo". Indivisa: Boletín de estudios e investigación 14 (2014): 44-52.

García-Baró, Miguel. Kant y herederos. Introducción a la historia de la filosofia occidental. Salamanca: Sígueme, 2019.

Spe Salvi, 48. Al principio del estudio, indicaba que la fe no es una hoja de ruta, sino un camino. Llegados al final del artículo, ese camino de renuncia hecho por Ratzinger-Benedicto XVI, es un camino hacia delante. Cf. Joseph Ratzinger, Introducción al cristianismo ( Salamanca: Sígueme, 2001),297: "El cristiano sabe que camina hacia delante, que no va haciendo círculos.. Pero durante el sueño resuena la voz de la realidad salvadora y transformadora (Jn 16,33) El mundo nuevo que se describe al final de la Biblia con la imagen de la Jerusalén celestial, no es una utopía, sino la certeza que nos ofrece la fe. El mundo ha sido redimido. Esa es la certeza que sostiene a los cristianos y que hace que hoy siga valiendo la pena ser cristiano." 
Gelbaert, Martín. “Una recepción teológica de la Spe Salvi”. Veritas 18 (2008): 31-46.

Gómez, Rafael. "Teología de la finitud y de la superación humanas". Scripta Teológica 15 (1972): 225-241.

Gómez de Pedro, María Esther. Libertad en Ratzinger. Riesgo y tarea. Madrid: Encuentro, 2014.

González, Olegario. "Los vuelcos en la Iglesia de Ratzinger a Bergoglio". Veritas 30 (2014): 129-161.

Grondin, Jean." La conclusión de la Crítica de la Razón Pura". Universitas philosophica. 49 (2007): 13-32.

Guardini, Romano. Apuntes para una biografia. Madrid: Encuentro, 1945.

Haeker, Th. Christentum und Kultur. München: Kösel, 1946.

Monda, Andrea. La humildad de Benedicto. Sus virtudes como Papa. Madrid: Cristiandad, 2013.

Newman, John Henry. Apología pro vita sua. Madrid: Encuentro, 2010.

Piñero, Ramón. "El amor como relación. reflexiones sobre el amor en algunos escritos de J. Ratzinger". Cauriensia 2 (2007): 305-342.

Platón. Timeo. Madrid: Gredos, 1992.

Prades, Javier. "El misterio de Dios contemplado y vivido por J. Ratzinger". Communio 7 (2007): 70-96.

Ratzinger, Joseph. Communio. Un programa teológico y eclesial. Madrid: Encuentro, 2013.

—. Mi vida. Recuerdos (1927-1977). Madrid: Encuentro, 1997.

-. Dios y el mundo. Barcelona: Galaxia Gutenberg- Círculo de Lectores, 2002.

-. "La iglesia en el umbral del tercer milenio". Revista Académica e Institucional Páginas de la UCP 98 (2015):123-132.

-. Introducción al cristianismo. Salamanca: Sígueme, 2001.

—. “PPor qué pertenezco a la iglesia?”. Revista Académica e Institucional, Páginas de la UCP 89 (2011): 85-87.

-. Homilía de la Misa de exequias de Juan Pablo II, el 8 de abril de 2015.

—. Juan Pablo II: Un Papa entre dos milenios. Barcelona: Lumen, 2000.

- Teoría de los principios teológicos. Materiales para una teología fundamental. Barcelona: Herder, 1985.

—. La fraternidad de los cristianos. Salamanca: Sígueme, 2004.

- "La contemplación de la belleza". Humanitas: revista de antropología y cultura cristiana 29 (2003). 8-10

Redzioc, Wlodzimierz. Junto a Juan Pablo II: Sus amigos y colaboradores nos hablan de él. Madrid: Ares, 2014. 
Romero, Adriana. "La concepción aristotélica de la eudaimonía en Ética a Nicómano. Relación entre vida activa y vida teorética". Revista de Investigación 85 (2005): 13-30.

Schlosser, Manfred. Teología de la oración. Salamanca: Sígueme, 2018.

Wansbrough, Henry. "La teología de J. Ratzinger", Revista de Libros, 130 (2007). 3-6

Seewald, Peter. Benedikt XVI - Ein Leben. Munchen: Droemer-Knaur, 2020.

—. Benedicto XVI. Una mirada cercana. Madrid: Palabra, 2006.

- La sal de la tierra. Cristianismo e Iglesia católica ante el nuevo milenio. Madrid: Palabra, 2005.

Sonnenfeld, Alfred. Serenidad. La sabiduría del gobernarse. Madrid: Rialp, 2018.

Vásquez, Francisco. "La menesterosidad laical de una teología de los signos de los tiempos”, Cuadernos de teología 6/1 (2014): 94-113.

-. Leyendo la Biblia con el Papa Francisco. Madrid: Cristiandad, 2018.

-. Juan Pablo II mi amado predecesor. Madrid: San Pablo, 2007.

—. Discurso a los Seminaristas de Roma, 20 de febrero de 2009.

-. Entrega del "Premio Ratzinger". En su primera edición. Discurso del Santo Padre Benedicto XVI. Sala Clementina, jueves 30 de junio de 2011.

-. Elogio de la conciencia. Madrid: Palabra, 2010.

-. Carta Encíclica sobre la esperanza cristiana, Spe Salvi, 2007.

Ángel Luis Lorenzo Francisco I. SS. CC. RR "Santa María de Guadalupe" Centro patrocinado UPSA Casa de la Iglesia. C/ General Ezponda, 14. 10003 Cáceres (España) https://orcid.org/0000-0002-3035-6142 
